\title{
Jeoid Değişimlerinin ICESat Altimetre Verisi ile Hesaplanan Su Seviyelerine Etkisi
}

\author{
Fatih SAKA ${ }^{1}$ \\ Ahmet Emre TEKELI ${ }^{2}$ \\ Senayi DÖNMEZ ${ }^{3}$
}

ÖZ

Çalışmada, ICESat uydusundaki GLAS altimetre verileriyle hesaplanan su seviye yüksekliklerine jeoid yüksekliklerinin etkileri Burdur Gölü (BG) üzerinde incelenmiştir. Su yüzeylerinin günlük olarak tespit edilebilmesi için MODIS uydusuna ait karla kaplı alan haritaları kullanılmıştır. ICESat verilerindeki Global EGM2008 jeoid ile hesaplanan ve BG yer gözlem ölçülerinin su seviye farkları $-0.96 \mathrm{~m}$ ile $-0.60 \mathrm{~m}$ aralığında olup hataların ortalama karekökü $0.73 \mathrm{~m}$ dir. Güncellenen jeoid ile hesaplanan su seviyelerinin hataları $\quad-0.20 \mathrm{~m}$ ile $0.16 \mathrm{~m}$ aralığında olup hataların ortalama karekökü $0.12 \mathrm{~m}$ 'ye inmiştir. DSİ yer gözlem verileri ile yapılan karşılaştırmada $\mathrm{R}^{2} 0.98$ olarak bulunmuştur. Birbirini takip eden kış ve yaz su seviye farkları $0.74 \mathrm{~m}$ hesaplanıp maksimum $1.0 \mathrm{~m}$ lik değişim içinde kalmıştır.

Anahtar Kelimeler: Burdur Gölü, jeoid, EGM2008, ICESat, GLA14, MODIS, lazer altimetresi.

\section{ABSTRACT \\ Effect of Geoid Variations on ICESat Altimeter Based Water Surface Elevations}

This study investigates the effects of geoid variations on GLAS altimeter onboard ICESat satellite based water surface elevations (WSE) over Burdur Lake (BL). MODIS snowcovered area maps are used to detect water surfaces daily. The differences between ground observations of BL WSE and those calculated using ICESat Global EGM2008 geoid varied between $-0.96 \mathrm{~m}$ and $-0.60 \mathrm{~m}$ with a root mean square error of $0.73 \mathrm{~m}$. The errors of recalculated water levels with the updated geoid heights varied from $-0.20 \mathrm{~m}$ to $0.16 \mathrm{~m}$ and the root mean square error decreased to $0.12 \mathrm{~m}$. Comparison with DSİ ground observations

\footnotetext{
Not: Bu yazı

- Yayın Kurulu'na 17 Ekim 2019 günü ulaşmıştır. 26 Haziran 2020 günü yayımlanmak üzere kabul edilmiştir.

- 31 Temmuz 2021 gününe kadar tartışmaya açıktır.

- https://doi.org/10.18400/tekderg.634227

1 Karabük Üniversitesi, İnşaat Mühendisliği Bölümü, Karabük - sakafatih@karabuk.edu.tr https://orcid.org/0000-0003-0956-8658

2 Iğdır Üniversitesi, İnşaat Mühendisliği Bölümü, Iğdır - aemre.tekeli@igdir.edu.tr https://orcid.org/0000-0001-9026-4373

3 Iğdır Üniversitesi, Ziraat Fakültesi, Iğdır - senayi.donmez@igdir.edu.tr https://orcid.org/0000-0002-8823-1131
} 
yielded $\mathrm{R}^{2}$ as 0.98 . Water level differences between the successive winter and summer is $0.74 \mathrm{~m}$ and remained within the maximum change of $1.0 \mathrm{~m}$.

Keywords: Lake Burdur, Geoid, EGM2008, ICESat, GLA14; MODIS; laser altimeter.

\section{GİRIŞ}

Su ve sulak alanlar hem insanlar hem de sulak alanlara ihtiyaç duyan hayvanlar ve özel bitki türleri için çok önemlidir. Günümüzde artan nüfus ve ihtiyaçlara paralel olarak azalan su kaynakları, küresel su hacminin \%2.5'inden az olan tatlı su kaynaklarının [1] ve sulak alanların sürdürülebilir yönetimini ve korunmasını çok daha önemli hale getirmiştir. Kısıtlı miktarda olan tatlı su kaynaklarının sürdürülebilir yönetimi için havzadaki depolanmış suyun, göller, sulak alanlar, nehirler ile rezervuarlar arasındaki su akılarının doğru bir şekilde hesaplanması gereklidir. Fakat havzaya olan girdilerin (yağmur, kar erimesi, nehir akımları) ve çıktıların (buharlaşma, sızma, su çekilmesi) ölçümlerindeki belirsizlikler su hacimlerinin doğru hesaplanmasını zorlaştırmaktadır [2]. Operasyonel çalışmalarda, su hacimlerinin hesabı yerine, tatlı su kaynakları olan göller ve baraj rezervuarlarının su seviye ölçümleri ile göl/rezervuar batimetrik haritalarının ilişkilendirilmesi ile su hacimleri bulunur.

Göl ve sulak alanlardaki su seviye ölçümleri önemli bilgiler sağlasa da Türkiye'de olduğu gibi küresel olarak yer gözlem ölçüm istasyonlarının sayısında bir azalma yaşanmaktadır [3]. Geriye kalan az sayıdaki göl gözlem istasyonlarının da aktif çalışır halde tutulması, çalışan istasyonlardan seviye verilerinin (ki ulusal ve uluslararası hassas bir bilgidir) alınması, farklı devlet kurumları arasında paylaşımı gibi konularda problemler yaşanabilmektedir [2].

Uydu tabanlı radar ve/veya lazer altimetre verileri iç suların su seviyelerinin ölçümlerinde yeni imkânlar sunmakla beraber, radar altimetrelerine (birkaç $\mathrm{km}$ ) nazaran daha dar ayak izlerine sahip lazer altimetrelerin $(70 \mathrm{~m})$ iç suların seviye ölçümlerinde daha doğru bilgiler sağlaması beklenmektedir [2]. Bununla beraber altimetre verileri elipsoidal yüksekliği vermekte olup, mühendislik ve çevresel uygulamalarda daha çok tercih edilen ve suyun akışını tahmin edilmesine imkân veren ortometrik yüksekliğe, doğru bir jeoid model kullanılarak çevrilmesi gerekmektedir [4].

Uydu tabanlı ilk lazer altimetresi olan Ice, Cloud and Land Elevation Satellite (ICESat, Buz, Bulut ve Kara Yüksekliği Uydusu) üzerinde olan Geoscience Lazer Altimetre Sistemi (GLAS) aktif çalıştığı 2003-2009 yılları arasında yüzey yükseklik ve ortometrik yükseklik hesabına imkân veren jeoid bilgilerini (EGM2008) sağlamıştır [5].

Gerek ICESat verileri ile yapılan çalışmalarda [4] gerekse global EGM2008 jeoid verilerinin bölgesel jeoid değerleri ile karşılaştırılmalarında [6-8] doğru ortometrik yüksekliklerin elde edilebilmesi için global EGM2008 jeoid bilgilerinin güncelleme gereklilikleri belirtilmiştir.

Global olarak ICESat ile iç su yükseklik değerlerinin çalışılmış olduğu birçok yayın olsa da, Türkiye'de ICESat ile iç su yüksekliklerinin çalışıldığı bir yayın Tekeli [9] tarafından yayınlanmıştır. Adı geçen çalışmada Akşehir Gölü su seviyeleri ICESat ile hesaplanmış fakat göl seviyesi eşel seviyesinin altına düştüğü için hesaplanan su seviyeleri bire bir yer gözlem ölçümleri ile karşılaştırılamamıştır.

Bu çalışmada, Türkiye ve Dünya için önemli sulak alanlardan birini içeren, Burdur Gölü (BG) su seviyeleri ICESat üzerinde olan GLAS'dan elde edilen lazer altimetre verileri 
kullanılarak hesaplanmış ve bulunan değerler yer gözlem değerleri ile karşılaştırılmıştır. Ayrıca, jeoid değişimlerinin ICESat altimetre tabanlı su seviye yüksekliklerine olan etkileri incelenmiştir.

\section{2.ÇALIȘMA ALANI}

Havza alanı $3264 \mathrm{~km}^{2}$ olan BG havzası, kapalı havza bir havza olup, içerisinde $248 \mathrm{~km}^{2}$ yüzey alanına sahip ve $37^{\circ} 49^{\prime} 15.53^{\prime \prime}-37^{\circ} 38^{\prime} 58.22^{\prime \prime K}$ enlemleri ile $30^{\circ} 3^{\prime} 30.21^{\prime \prime}$ $30^{\circ} 20^{\prime} 33.51$ "D boylamları arasında olan BG'ne sahiptir. BG, Türkiye'nin 14 Ramsar alanından (uluslararası öneme sahip sulak alan) biri olarak tescillenmiş olup aynı zamanda Yaban Hayatı Geliştirme Sahası statüsüne sahiptir [10,11]

Burdur Havzasının ikliminde Akdeniz iklimi ile Karasal iklim arasında geçiş özelliğinin egemen olduğu görülür. Buna göre, yaz mevsimi sıcak ve kurak, kış mevsimi ise oldukça soğuk geçmektedir [12]. 1932-2019 yılları arasında yıllık yağış toplamı ortalaması $428 \mathrm{~mm}$ bulunmuş̧ur [13]. Burdur ili meteorolojik değerlerinin 1932-2019 yılları arası için aylık ortalama değerleri Şekil 1 de gösterilmiştir.

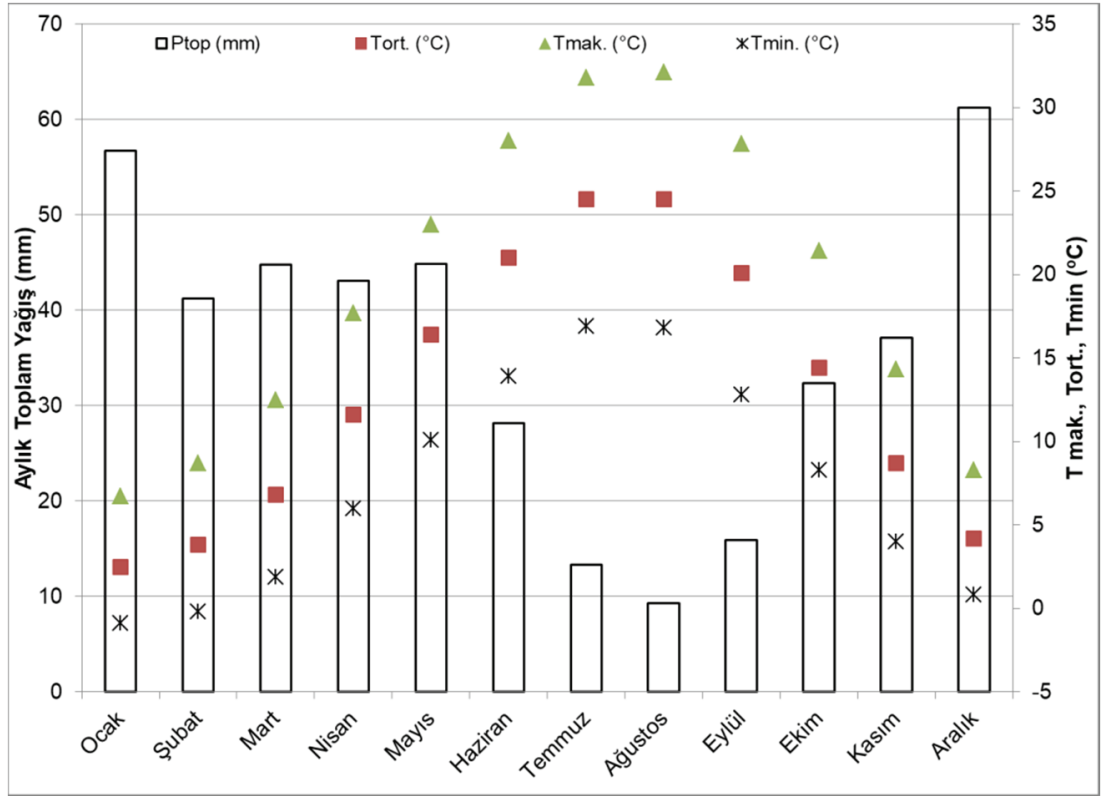

Şekil 1 - Burdur ili 1932-2019 arası aylık toplam yağış, ortalama slcaklık (T) değerleri.

Göl sularının kışın donmaması, güneybatı ve kuzeydoğu uçlarında sığ kesimlerin olması çamur düzlükleri zengin besin varlı̆̆ı ile kuşların beslenmesine yardımcı olmaktadır. BG'de iki endemik balık türü yaşamaktadır, ayrıca Türkiye kuş türlerinin \%57'sini barındırmaktadır. BG'nin biyocoğrafik açıdan en büyük önemi, nesli dünya çapında tehlikede olan Dikkuyruk Ördek'in dünyadaki popülasyonunun yaklaşık \%70'inin gölde bulunmasindan gelmektedir [14]. 
Türkiye'nin göl büyüklüğü açısından yedinci büyük gölü olan [15] BG, Göller Bölgesi’nin en büyük gölleri arasında yer alan tektonik bir göldür. Güneybatı ve kuzeydoğu yönlerinde alüvyal birikim nedeniyle tuzlu bataklıklar bulunmaktadır. Gölün kıyı alanı dar ve hızla derinleşmektedir. Gölün beslenmesinde, yağışın doğrudan oranı yaklaşık \%40, akarsulardan gelen suyun oranı ise yaklaşık \%55 olduğu belirlenmiştir. Havzaya düşen yağışlar BG çanağında toplanmaktadır. Göl güneybatı ve kuzeydoğusundaki yeraltı suları ve yağış suları ile beslenmekte, buharlaşma ile de su kaybetmektedir. Ancak bu dengenin bozulmasıyla göl küçülmektedir [16]. Özellikle kuşların konakladığı sığlık alanlarda su seviyelerinde azalma görülmektedir. Ayrıca su miktarının azalmasıyla, hem kirlilik etkileri hem de göldeki tuzluluk oranı artış göstermektedir. 1970-2002 yılları arasında su seviyesinin 857m den 845m ye 12 m'lik alçalması göldeki tuzluluğu yaklaşık iki kat artırdığı gözlenmiştir [17]. Ataol [16] tarafından yürütülen çalışmalarda ise, Eylül 2008'de göl seviyesinin 844 m olduğu belirlenmiştir.

Göller Bölgesi'ndeki birçok göl gibi BG'de de azalan su seviyeleri gözlenmektedir [15, 16, 18, 19]. Şekil 2'de, BG'nin yüzey alanının yıldan yıla değişimi, 1994(a), 2016(b) ve 2019(c) yıllarına ait Google Earth (GE) görüntülerinde görülmektedir. Gölün kuzeydoğu kısmındaki çekilme diğer taraflara nazaran daha açık olarak görülmektedir.

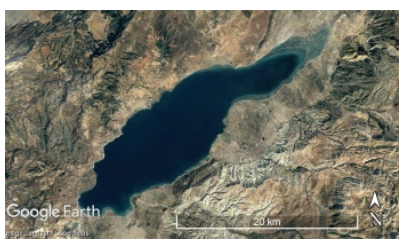

(a)

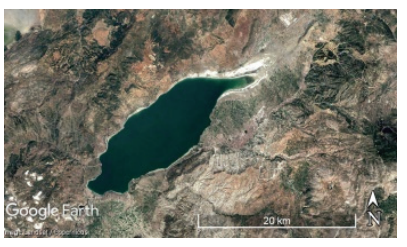

(b)

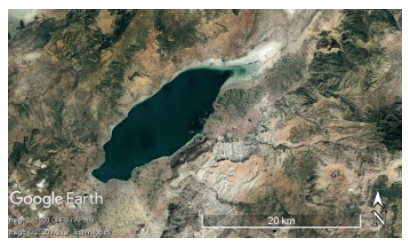

(c)

Şekil 2 - BG yüzey alanının 1994 Aralık (a), 2016 Aralık (b) ve 2019 Ağustos (c) aylarındaki Google Earth görüntüleri.

BG'den, içme-kullanma ve sulama amacıyla su çekilmemektedir. Fakat BG'yi besleyen alt havzalardaki su yapıları ile y1llı toplam 28.4 milyon $\mathrm{m}^{3}$ sulama suyu şebekelere verilmektedir [15]. Ataol [16] 2010 yılındaki çalışmasında, göl şartlarının devamı halinde 2080 yılındaki göl seviyesinin 25 metre daha alçaldıktan sonra derin bir çanakta, aşırı tuzlu ve kuşlar için gerekli sazlıkların oluşumuna uygun sı̆̆ kıyılardan yoksun, 80 km²'lik alana sahip bir su kütlesi olarak varlığını sürdüreceğini öngörmektedir. Yine Keskin vd. [15], 2015 yılında yaptıkları bir araştırmada, BG'de gerekli önlemler alınmazsa, 100 yıl sonra su seviyesindeki azalmanın 31.5 m'yi bulabileceği ve derinlik değerlerinin az olduğu yerlerde suların tamamen kuruyacağına vurgu yapılmıştır.

\section{VERI SETLERI}

\subsection{ICESat GLA14}

Zwally vd. [20] de belirtildiği gibi ICESat üzerinde bulundurmuş olduğu GLAS ile lazer altimetre verileri sağlayan ilk uydudur. ICESat, GLAS ile, karalar, su kütleleri, bitki, aerosol ve bulut yüksekliklerini ölçebilmiş özellikle de, buzulların ve deniz buzları ölçümlerinde 
referans verileri oluşturabilecek bilgilerin elde edilmesine imkan sağlamıştır [5]. GLAS, $600 \mathrm{~km}$ orbit yüksekliğinden, yeryüzü üzerinde her $172 \mathrm{~m}$ 'de 70 metre çaplı ayak izleri içerisinde ölçümler yapmaktadır. Şekil 3'de ICESat uydusunun 25 Mayıs 2006 tarihinde Türkiye üzerinden geçişi gösterilmiştir.

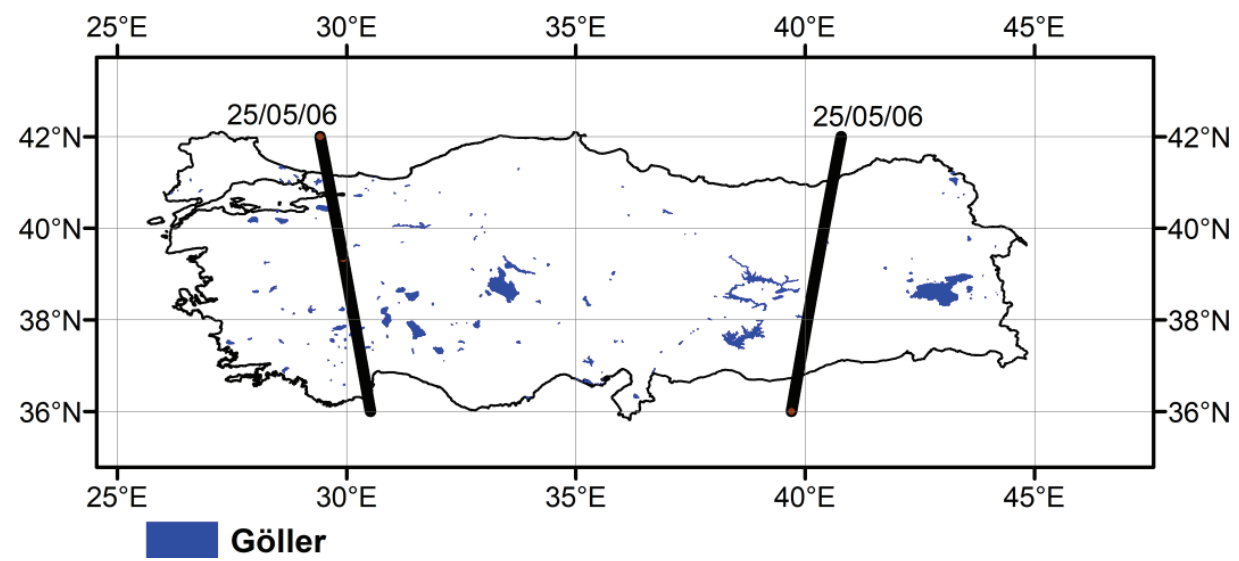

Şekil 3 - ICESat uydusu GLAS sensöründen elde edilen GLA14 verilerinin 25 Mayls 2006 tarihinde Türkiye üzerindeki geçişleri.

$\mathrm{Bu}$ ölçümlerde yüzey altimetresi ve yoğun bulut tepeleri için $1064 \mathrm{~nm}$ pulse, ince bulut ve aerosollerin tabakalarının düşey dağılımı için $532 \mathrm{~nm}$ pulse kullanılmıştır [21]. GLAS, ilgili lazer pulse'nın uydudan çıkıp yer yüzeyinden yansıyarak tekrar uyduya dönmesi arasında geçen zamanı ölçerek, yer yüzeyi ile arasındaki aralık vektörünü hesaplar. GLAS yörünge parametrelerinden, hesaplanan aralık vektörünün çıkarılması ile yer yüzeyi yüksekliği bulunur. Bulunan yükseklik, bulut etkisi ve diğer bazı kalite kontrol testlerini geçebildiği durumlar için kullanıcılara sunulur. GLAS ile yapılan yükseklik hesaplamalarının fiziksel ve matematiksel detayları algoritmaların teorik dokümanlarından [22] elde edilebilir.

Deniz buzları ve göl seviyeleri gibi düz alanlar için ICESat GLAS ölçümlerinden elde edilen yüzey yükseklik ölçümlerinin yüksek doğruluğu $(2 \sim 10 \mathrm{~cm}$ olarak $)$ literatürde belirtilmiştir [23-25]. Bu çalışmada, kara yüzeylerinde yükseklik ölçümlerini sağlayan GLAS / ICESat L2 Global Land Surface Altimetry Data (GLA14)'ün sürüm 33'ü kullanılmıştır. GLA14 V33 verileri National Snow and Ice Data Center (NSIDC) 'den elde edilmiştir.

\subsection{Burdur Gölü Su Kaplı Alanların Belirlenmesi}

ICESat altimetre verileri sağladığı ve görüntüleme sensörlerine sahip olmadığı için ICESat ayak izlerinin ne tür yeryüzü örtüsü üzerine düştüğünün tespiti amaciyla diğer uydu verilerine ihtiyaç duymaktadır. Çalışma konumuz su yüzeylerinin seviye tespiti olduğu için ICESat verilerinin su yüzeylerindeki ayak izlerinin bulunması gerekmektedir. Bunun için; Duan ve Bastiaanssen [2] Landsat TM/ETM+ uydu verilerini, Song vd. [26] Landsat uydu verilerini, Zhang vd. [27] MODIS uydusundan elde edilen MODIS karla kaplı alan haritalarını kullanmışlardır. 
Her ne kadar Duan ve Bastiaanssen [2] Landsat verilerini kullanmış olsalar da, yazarlar çalışmalarında 16 günlük zamansal periyoda sahip Landsat verilerinin operasyonel çalışmalar için fazla uzun bir süre teşkil ettiğini bahis etmişlerdir. Ayrıca, Song vd. [26] çalışmalarında su yüzlerini kendileri çıkarmamışlar, bu bilgiyi daha önceki Song vd. [28] çalışmalarından elde etmişlerdir.

Terra uydusunda, Moderate Resolution Imaging Spectroradiometer (MODIS), olarak adlandırılan ve $250 \mathrm{~m}$ ila $1000 \mathrm{~m}$ arasında değişen mekânsal çözünürlüklerle $0.4 \mu \mathrm{m}$ ile 14.4 $\mu \mathrm{m}$ aralığında 36 dar spektrum bandında Dünya gözlemlerine olanak tanıyan bir sensör vardır. $2330 \mathrm{~km}$ şerit genişliğine sahip olan MODIS sensörü ile 1 ila 2 gün içerisinde tüm Dünya taranabilmektedir. Bu taramalardan elde edilen verilerden, MODIS kar kaplı alan (KKA) haritaları, MODIS kalibre edilmiş radyans verilerini (MOD02HKM), jeolokasyon (MOD03) ve bulut maskesi ürünlerini (MOD35_L2) girdi olarak [29] kullanan ve [30] tarafindan geliştirilen algoritma ile üretilmektedir.

$\mathrm{Bu}$ çalışmada ICESat altimetre verilerinin su üzerindeki ayak izlerinin tespiti için, çeşitli MODIS ürünleri arasından Zhang vd. [27] ile Tekeli [9]'a benzer şekilde, MODIS Snow Cover Daily L3 Global 500m Grid (MOD10A1) verileri kullanılmıştır. Günlük olarak üretilen MODIS KKA haritalarında 500m yersel çözünürlüklü pikseller Tablo 1 de gösterilen sinıflarından birine atanır [29].

MODIS KKA haritalarının yüksek doğrulukta olduğu birçok çalışmada belirtilmiştir [31-33]. Bunlara ek olarak, MODIS KKA haritalarının Türkiye üzerinde kullanılabilirliği yapılan çalışmalarda [34-38] gösterilmiştir. Bu çalışmada MOD10A1 verilerinden sürüm 5 (V5) kullanılmıştır [39].

Tablo 1 - MODIS L3 Global 500m KKA haritalarındaki sinıflar.

\begin{tabular}{cccc}
\hline Pikselin sayısal değeri & Sınıf & Pikselin sayısal değeri & Sınıf \\
0 & Eksik veri & 39 & Okyanus \\
1 & Karar verilemedi & 50 & Bulut \\
11 & Gece & 200 & Kar \\
25 & Kara & 254 & Doygun sensör \\
37 & Göl & 100 & Göl buzu \\
\hline
\end{tabular}

\section{METODOLOJI}

Şekil 4'de verilen akış şeması kapsamında, NSIDC'dan elde edilen binary (ikili) formattaki dosyalardaki veriler, Türkiye sınırları için kesilmiş, GE'de gösterimine imkân kılan kmz formatına çevrilmiştir. Kmz formatına çevrilen ICESat GLA34 V33 verileri, GE'de açılarak, BG üzerinden geçiş tarihleri belirlenmiştir. Tablo 2 ICESat verilerinin BG üzerinden geçtiği günleri özetlemektedir. Çalışma aralığı olan 2003-2009 yılları arasında BG üzerinden toplam 15 ICESat geçişi bulunmuştur. ICESat uydusunun 25 Mayıs 2006 tarihine ait BG üzerindeki geçişinin GE üzerinde gösterimi Şekil 5'de verilmiştir. Tekeli [9]'da, Akşehir Gölü su yüzeyi üzerine düşen ICESat ayak izlerinin tespiti için, ICESat'ın Akşehir Gölü üzerinden geçiş gününe ait MODIS KKA haritalarında göl olarak tanımlanan pikseller kullanılmıştır. Bu 
çalışmada BG'nün sulu alanlarının tespiti için, Tekeli [9]'a benzer şekilde, ICESat'ın BG üzerinden geçiş tarihlerine ait günlük MOD10A1 KKA haritaları NSIDC'den indirilmiş, işlenmiş ve göl olarak tanımlanmış pikseller belirlenmiştir.

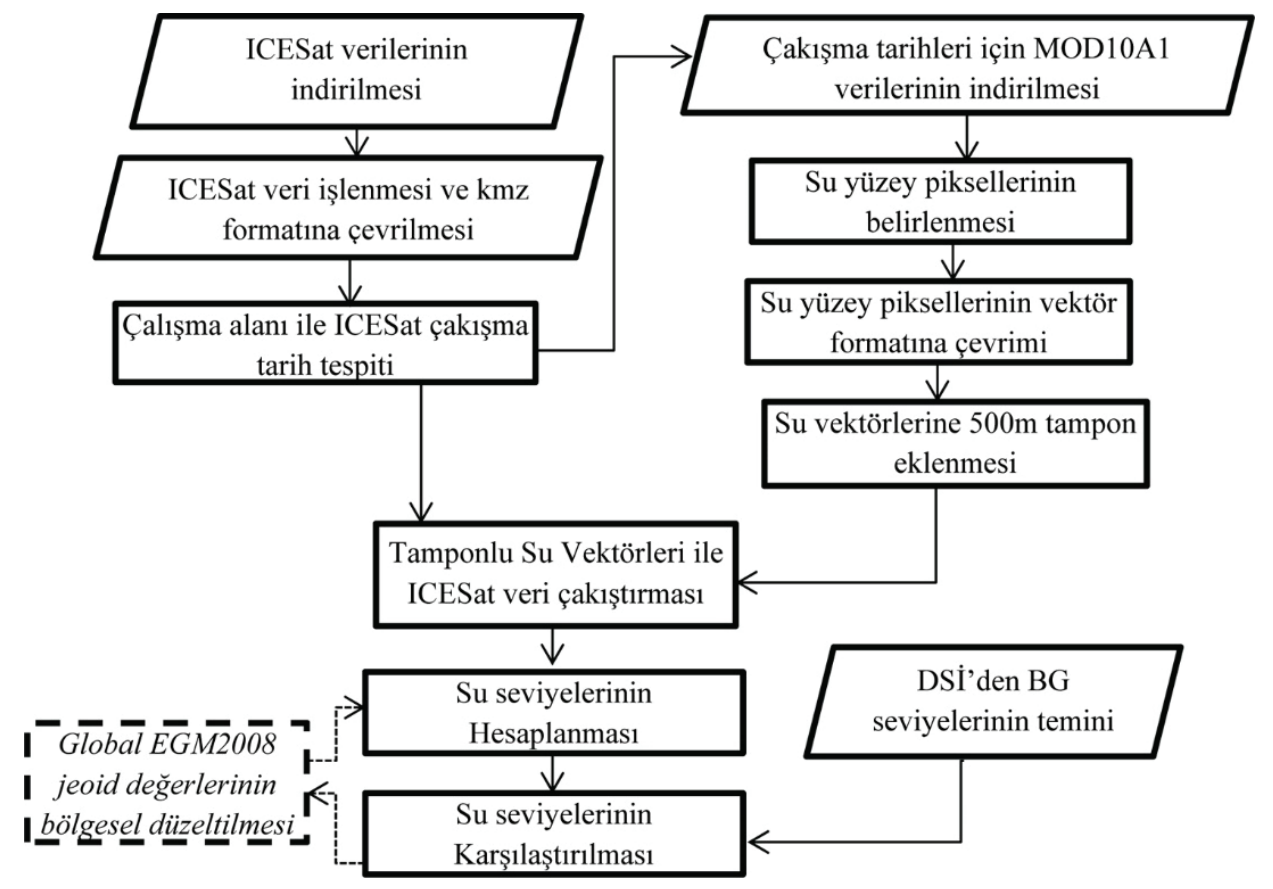

Şekil 4 - Uygulanan metodolojinin akışş̧eması.

Tablo 2 - ICESat GLA34 V33 verilerinin BG ile çakışma tarihleri ve BG üzerine düşen ICESat ayak izleri saylst.

\begin{tabular}{cccc}
\hline Tarih & $\begin{array}{c}\text { Ölçüm } \\
\text { Sayıları }\end{array}$ & Tarih & $\begin{array}{c}\text { Ölçüm } \\
\text { Sayıları }\end{array}$ \\
\hline $17 / 10 / 2003$ & $\mathbf{1 1}$ & $25 / 05 / 2006$ & $\mathbf{4 5}$ \\
$18 / 02 / 2004$ & $*$ & $26 / 10 / 2006$ & $\mathbf{2 9}$ \\
$19 / 05 / 2004$ & $*$ & $13 / 03 / 2007$ & $\mathbf{4 1}$ \\
$05 / 10 / 2004$ & $\mathbf{1 9}$ & $03 / 10 / 2007$ & $\mathbf{4 0}$ \\
$20 / 02 / 2005$ & $*$ & $18 / 02 / 2008$ & $*$ \\
$21 / 05 / 2005$ & $*$ & $05 / 10 / 2007$ & $*$ \\
$22 / 10 / 2005$ & $\mathbf{3 7}$ & $01 / 10 / 2009$ & $\mathbf{4 1}$ \\
$23 / 02 / 2006$ & $\mathbf{4 7}$ & & \\
\hline
\end{tabular}

* Tablo 3'deki açıklamaya bakınız. 
MODIS, KKA haritalarından su yüzeyleri olarak tanımlanan pikseller raster veri formatında çekilmiştir (Şekil 6a). Şekil 6a aynı zamanda ilgili gündeki ICESat verilerini göstermektedir (yeşil noktalar). Elde edilen raster verilerden çalışma alanlarına ait su yüzeyleri vektör formatına çevrilmiştir (Şekil 6b). Tekeli vd. [35] belirtilen karışık pikselleri engellemek için Tekeli [9]'da uygulanan 500m lik tamponlar elde edilen su yüzey vektör dosyalarına uygulanmıştır (Şekil 6c). Su yüzeylerinin yükseklik değerlerinin bulunmasında, MODIS KKA görüntülerindeki su yüzeyleri üzerinde (Şekil 6a) ve $500 \mathrm{~m}$ lik tamponun dişında kalan (Şekil 6c) ICESat ayak izleri (pembe noktalar) kullanılmıştır (Şekil 6d).

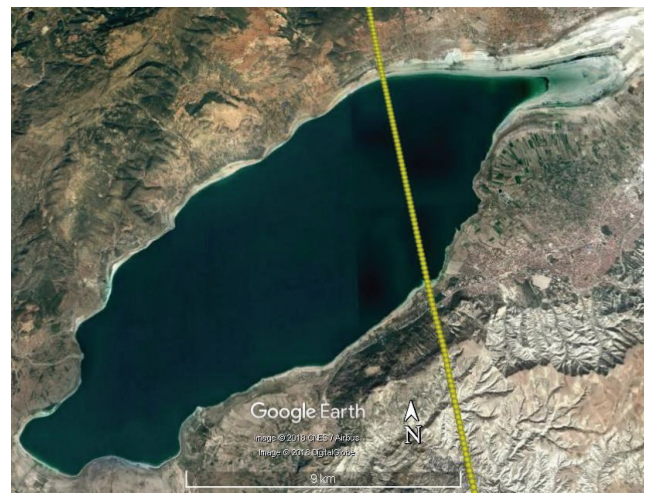

Şekil 5 - Google Earth ortamında Burdur Gölü üzerinden 25/05/2006 tarihli geçişteki ICESat ayak izlerinin gösterimi.

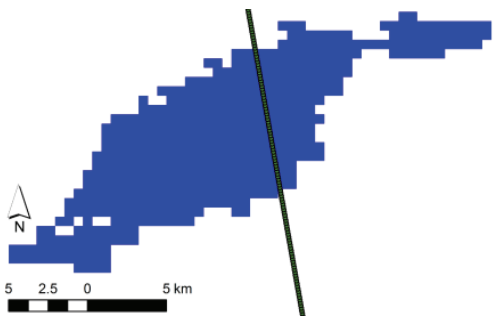

(a)

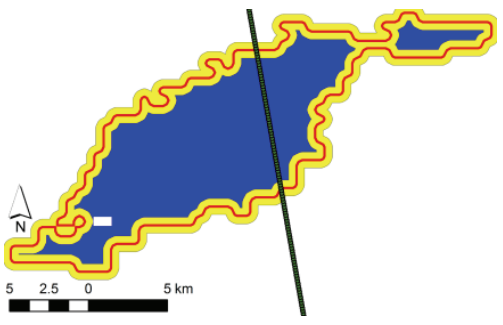

(c)

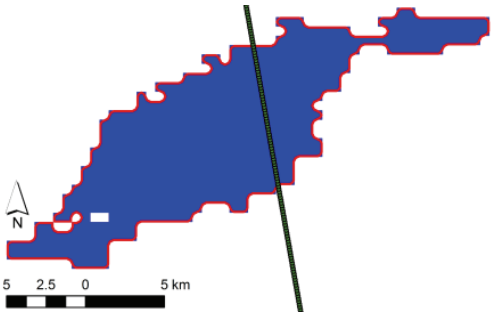

(b)

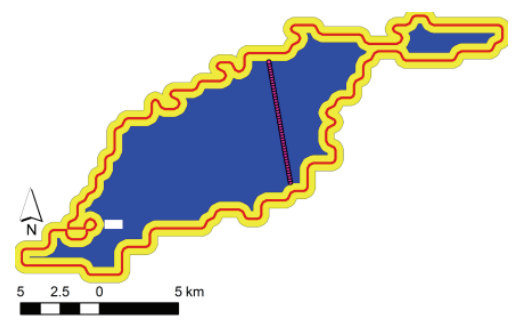

(d)

Şekil 6 - MODIS KKA haritalarından elde edilen raster su yüzeyleri ile ICESat ayak izleri (yeşil noktalar) (a), MODIS KKA haritalarından elde edilen su yüzeyi vektörü (b), Su yüzey vektörlerine uygulanan $500 \mathrm{~m}$ lik tamponlar (c) 500 tampon bölgenin dışında ve su yüzeyinde kalan ICESat ayak izleri (pembe noktalar)(d). 


\section{BULGULAR}

Şekil 4'de verilen akış şemasında gösterilen (italik olmayan kısımlar) ve metodoloji kısmında açıklandığı şekilde ICESat GLAS GLA14 verilerinden elde edilen su yüzeyi yükseklik değerleri Tablo 3'de özetlenmiştir. Tablo 3'deki tarih kolonu, ICESat uydusunun ilgili su yüzeylerinden geçiş tarihini, DSİ kolonu ilgili tarihte ilgili su yüzeyi için Devlet Su İşleri (DSİ) Genel Müdürlügü̈'nden elde edilen su yüzey seviyelerini göstermektedir. ICESat Global EGM2008 kolonu altındaki H (m) kolonu, GLA14 yükseklik ve Global EGM2008 verilerinden hesaplanan su seviye yüksekliklerinin medyan değerini, ss (m) kolonu ise hesaplanan su seviyelerindeki standart sapmayı belirtmektedir. ICESat GLA14'den elde edilen su seviye yükseklikleri denklem 1 kullanılarak hesaplanmıştır.

Su Yüksekliği= Elipsoidal Yükseklik - Jeoid Yüksekliği

Denklem 1'de Elipsoidal yükseklik; ICESat verisinden elde edilmiş yükseklik ve jeoid yüksekliği ise ICESat verileri ile sağlanmış global EGM2008 jeoid verilerin Topex/Poseidon elipsoidine göre sağlanmış değerleridir.

Tablo 3 - ICESat GLAS verilerinden elde edilen su yüzey yüksekliklerinin yer gözlemleri ile karşılaştırılması.

\begin{tabular}{|c|c|c|c|c|c|c|c|}
\hline \multirow[t]{2}{*}{ Tarih } & \multirow{2}{*}{$\begin{array}{l}\text { DSI } \\
\text { (m) }\end{array}$} & \multicolumn{2}{|c|}{$\begin{array}{c}\text { ICESat } \\
\text { Global } \\
\text { EGM2008 }\end{array}$} & \multirow{2}{*}{$\begin{array}{l}\text { Fark } \\
\text { (m) }\end{array}$} & \multicolumn{2}{|c|}{$\begin{array}{c}\text { ICESat } \\
\text { Bölgesel } \\
\text { EGM2008 }\end{array}$} & \multirow{2}{*}{$\begin{array}{c}\text { Fark } \\
\text { (m) }\end{array}$} \\
\hline & & $\mathrm{H}(\mathrm{m})$ & ss (m) & & $H(m)$ & $s s(m)$ & \\
\hline $17 / 10 / 03$ & 845.44 & 844.71 & 0.14 & -0.73 & 845.47 & 0.14 & 0.03 \\
\hline $18 / 02 / 04$ & 846.13 & $!$ & $!$ & $!$ & $!$ & $!$ & $!$ \\
\hline $19 / 05 / 04$ & 846.57 & $!$ & $!$ & $!$ & $!$ & $!$ & ! \\
\hline $05 / 10 / 04$ & 846.04 & 845.38 & 0.03 & -0.66 & 846.14 & 0.03 & 0.10 \\
\hline $20 / 02 / 05$ & 846.11 & $!$ & $!$ & $!$ & $!$ & $!$ & $!$ \\
\hline $21 / 05 / 05$ & 846.23 & \# & \# & \# & \# & \# & \# \\
\hline $22 / 10 / 05$ & 845.69 & 845.09 & 0.66 & -0.60 & 845.85 & 0.66 & 0.16 \\
\hline $23 / 02 / 06$ & 845.66 & 845.04 & 8.10 & -0.62 & 845.80 & 8.10 & 0.14 \\
\hline $25 / 05 / 06$ & 845.75 & 845.03 & 0.86 & -0.72 & 845.79 & 0.86 & 0.04 \\
\hline $26 / 10 / 06$ & 845.27 & 844.31 & 0.31 & -0.96 & 845.07 & 0.31 & -0.20 \\
\hline $13 / 03 / 07$ & 845.26 & 844.59 & 0.03 & -0.67 & 845.35 & 0.03 & 0.09 \\
\hline $03 / 10 / 07$ & 843.57 & 843.90 & 0.85 & 0.33 & 844.66 & 0.85 & 1.09 \\
\hline $18 / 02 / 08$ & 843.51 & $!$ & $!$ & $!$ & $!$ & $!$ & ! \\
\hline $05 / 10 / 08$ & 842.93 & $!$ & $!$ & $!$ & ! & $!$ & ! \\
\hline 01/10/09 & 843.58 & 842.76 & 0.11 & -0.82 & 843.52 & 0.10 & -0.06 \\
\hline
\end{tabular}

! MODIS karla kaplı uydu görüntüsü bulut kaplı

\# Su yüzeyi üzerinde ICESat verisi yok 
Tablo 3'deki Fark (m) kolonu ise, DSİ ile ICESat su seviye yükseklik farklarını vermektedir. Şekil 7 BG için ICESat ile DSİ'den elde edilen su seviye yükseklikleri göstermektedir. DSİ ve ICESat su seviyeleri aralarındaki en büyük ve en küçük farklar; $-0.96 \mathrm{~m}$ ve $+0.33 \mathrm{~m}$ olup hataların ortalama karekökü (HOKK) $0.70 \mathrm{~m}$ dir.

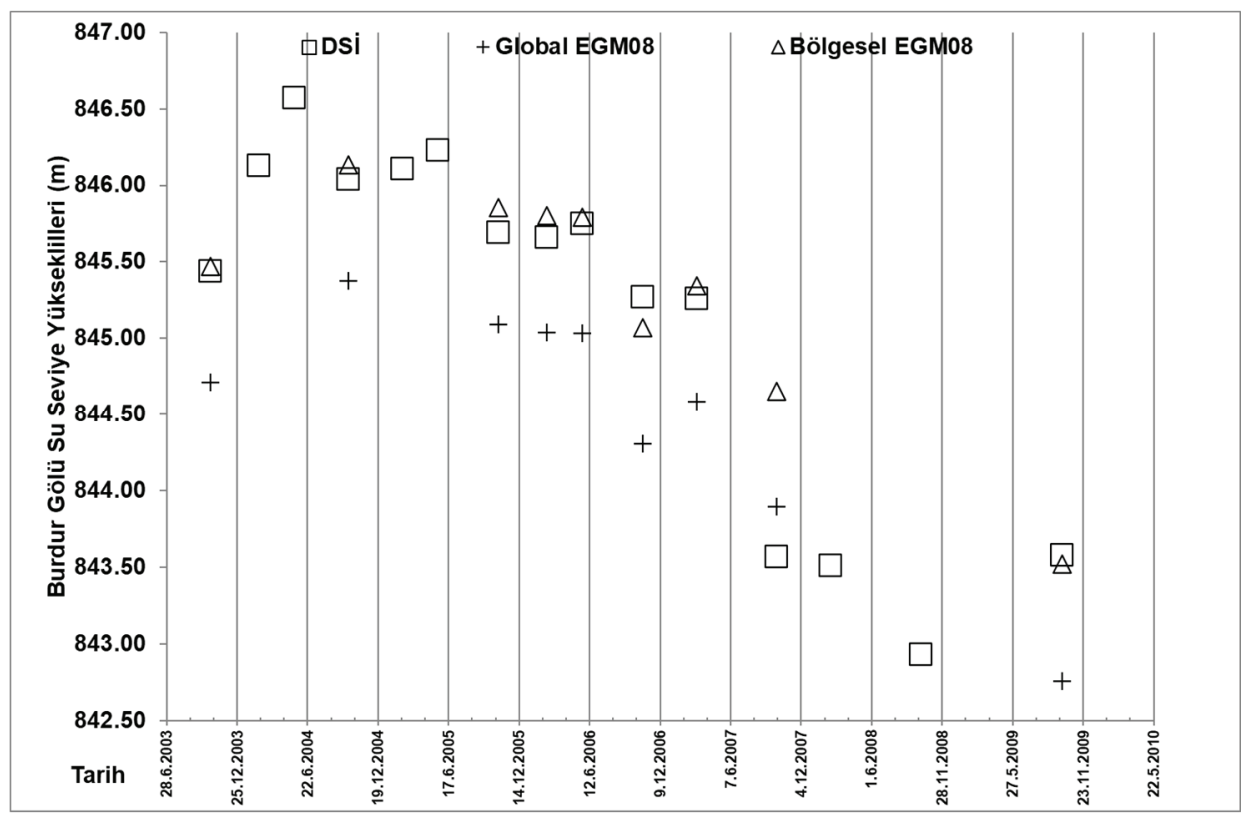

Şekil 7 - Burdur Gölü için ICESat ve DSİ su seviye değerlerinin karşılaştırılması.

Tablo 4 farklı araştırmacılar tarafindan ICESat verileri kullanılarak hesap edilmiş su seviyelerinin yer verileri ile karşılaştırma sonuçlarını özetlemektedir.

Rao vd. [6] 2012'de, Hindistan üzerinde farklı iki bölgede yapılan çalışmalarda ortometrik yüksekliklerde jeoid farklarından dolayı su seviyeleri arasındaki farkların -1.08m ile $1.42 \mathrm{~m}$ arasında olabileceğini göstermiştir. Yapılan literatür taramasında çalışma bölgesindeki jeoid değerlerinin global EGM2008 jeoid değerlerinden $0.76 \mathrm{~m}$ daha az olduğu belirtilmiştir $[7,8]$. Bu bilgi ışığında global EGM2008 değerlerinde 0.76m düşülerek ve denklem 1 kullanılarak yeniden BG su seviyeleri hesaplanmıştır. Bu işlemler Şekil 4'de verilen akış şemasında italik formatta ve kesik çizgili işlem adımları ile belirtilmiştir. Yeni hesaplanan su yükseklikleri, ss ve farklar Tablo 3'de italik olarak bölgesel EGM2008 kolonu altında verilmiş ve Şekil 7'de grafiksel olarak gösterilmiştir.

Yeni hesaplanan değerlere göre su seviyelerindeki hata $(-0.20 \mathrm{~m}, 1.09 \mathrm{~m})$ arasında değişiklik göstermiş ve HOKK $0.38 \mathrm{~m}$ olmuştur (Tablo 4). Bu hata değeri literatürde ICESat [3] ile yapılmış su seviyelerinde bulunan $0.25-0.27 \mathrm{~m}$ hata mertebesine yakındır. Tablo 3 'de 3 Ekim 2007 tarihine ait $1.09 \mathrm{~m}$ farkın dişındaki farklar [-0.20m, $0.16 \mathrm{~m}]$ kabul edilebilir seviyede ve HOKK $0.12 \mathrm{~m}$ olup literatürde belirtilen aralıklarda kalmaktadır (Tablo 4). Şekil 8, bölgesel EGM2008 değerleri ile hesaplanan su seviyeleri ile DSİ'den sağlanan yer gözlem ölçülerinin saçılma grafiğini göstermektedir. 
Tablo 4 - Literatürdeki farklı ICESat GLAS çalışmalarından derlenen su yüzey yüksekliklerinin yer gözlemleri ile karşılaştırılması.

\begin{tabular}{|c|c|c|c|c|}
\hline \multicolumn{2}{|c|}{ FARK } & \multirow{2}{*}{$\begin{array}{c}\text { Hataların ortalama kare } \\
\text { kökü } \\
(\mathrm{HOKK}, \mathrm{cm})\end{array}$} & \multirow[b]{2}{*}{$\mathrm{R}^{2}$} & \multirow[b]{2}{*}{ Araştırmacı } \\
\hline $\begin{array}{c}\text { En küçük } \\
(\mathrm{cm})\end{array}$ & $\begin{array}{c}\text { En Büyük } \\
(\mathrm{cm})\end{array}$ & & & \\
\hline-- & -- & 35 & 0.99 & \multirow{3}{*}{ Duan ve Bastiaanssen [2] } \\
\hline-- & -- & 10.5 & 0.97 & \\
\hline-- & -- & 87 & 0.06 & \\
\hline 2 & 21 & 8 & 0.90 & Zhang vd. [3]* \\
\hline-- & -- & 7 & -- & Jiang vd. [4]** \\
\hline-96 & $33 * * *$ & 70 & 0.84 & \multirow{2}{*}{$\begin{array}{c}\text { Bu çalışma } \\
\text { Global EGM2008 }\end{array}$} \\
\hline-96 & -60 & 73 & 0.98 & \\
\hline-20 & $109 * * *$ & 38 & 0.84 & \multirow{2}{*}{$\begin{array}{c}\text { Bu çalışma } \\
\text { Bölgesel EGM2008 }\end{array}$} \\
\hline-20 & 16 & 12 & 0.98 & \\
\hline
\end{tabular}

\footnotetext{
* $30 \mathrm{~cm}$ den fazla standart sapmaya neden olan veriler atılmıştır

** Medyan değerinin $\pm 2.965 x$ (medyandan sapmaların mutlak değerlerinin medyanı) aralığındaki değerler alınmıştır.
}

*** 03/10/07 tarihinde çok fazla düşüş gösteren, hatalı olabilecek ölçüm değeri varken

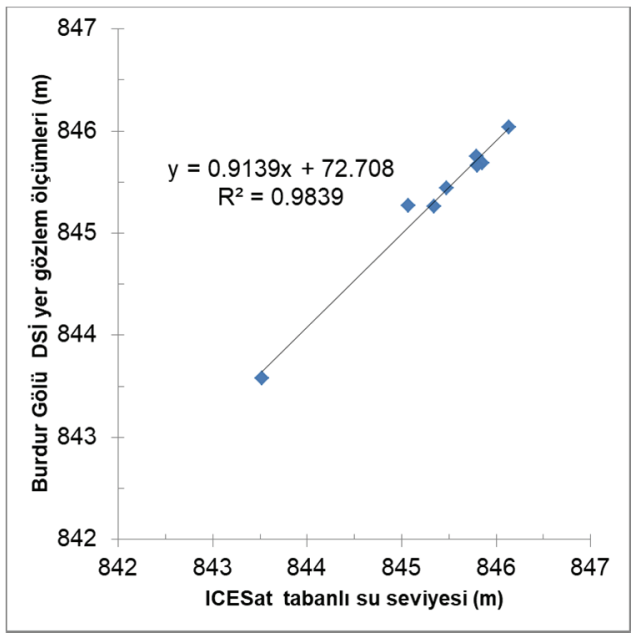

Şekil 8 - BG için bölgesel EGM2008 kullanılarak hesaplanan ICESat su seviyeleri ile DSI yer gözlemlerinin saçılma grafiği (3 Ekim 2007 tarihli DSI gözlem değeri hatalı olduğu düşüncesi ile atılmuştır). 
DSİ'den elde edilen BG'nin göl su seviye yer gözlem ölçümleri incelendiğinde, 30 Eylül 2007'den 1 Ekim 2007'ye geçişte su seviyesi $844.60 \mathrm{~m}$ den $843.58 \mathrm{~m}$ ye inerek, $1.02 \mathrm{~m}$ lik bir düşüş göstermiştir (Şekil 9). ICESat tabanlı hesaplamalarda 3 Ekim 2007 ait 1.09m'lik hatanın bu düşüşten kaynaklandığı düşünülmektedir.

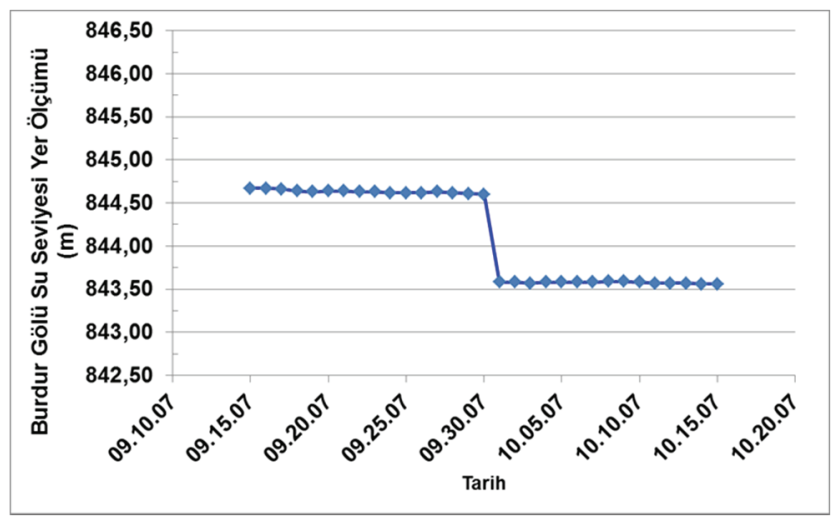

Şekil 9. BG için DSİ su seviye gözlemleri.

Tablo 3'de 23 Şubat 2006 tarihi için su seviyesi hesaplamalarında yüksek ss $(8.10 \mathrm{~m})$ gözlenmiş olsa da, hesaplamalarda medyan değerleri kullanıldığından, hata değeri $0.14 \mathrm{~m}$ mertebesinde kalmıştır. Birbirini takip eden kış ve yaz su seviyeleri olarak alınabilecek 23/02/2006 (845.80m) ile 26/10/2006 (845.07m) tarih ve değerler ile yaz ve kış su seviye farkı yaklaşık $0.73 \mathrm{~m}$ bulunur. Bu değer Koçıbay [40]'da belirtilen 1m'nin altındadır.

\section{SONUÇLAR}

Çalışma kapsamında yapılan literatür taramalarında, ICESat uydusu GLAS sensöründen elde edilen yükseklik verilerinin daha önce Türkiye'de iç sulardaki doğruluk analizlerinin yer ölçüm verileriyle karşılaştırılarak gerçekleştirilmediği görülmüştür. Dolayısıyla çalışma mevcut literatüre yeni bir katkı sağlamaktadır.

GLA14 veri setinde gelen Global EGM2008 jeoid yükseklikleri ile hesaplanan hata değerleri iki farklı şekilde ele alınmıştır. Bunlardan ilkinde 03/10/07 tarihinde çok fazla düşüş gösteren, hatalı olabilecek ölçüm değeri de dikkate alınarak, diğeri ise bu değerin göz ardı edilmesi ile elde edilen sonuçlardır (Tablo 4). İlk durumda; Global EGM2008 ölçümleri ile [-0.96m ile $0.33 \mathrm{~m}]$ aralığında olup, hataların ortalama kare kökü $0.70 \mathrm{~m}$ olarak bulunmuştur. Bölgesel EGM2008 jeoid yükseklikleri ile hesaplamaların yeniden yapılması ile hata değerleri $[-0.20 \mathrm{~m}$ ile $1.09 \mathrm{~m}]$ aralığında bulunmuş ve HOKK değeri $0.38 \mathrm{~m}$ olarak belirlenmiştir. İkinci durumda ise; Global EGM2008 ölçümleri ile [-0.96m ile -0.60] aralığında bulunmuştur. Bölgesel EGM2008 jeoid yükseklikleri ile hesaplamaların yeniden yapılması ile hata değeri $[-0.20 \mathrm{~m}$ ile $0.16 \mathrm{~m}]$ aralığında bulunmuş hataların ortalama kare kökü $0.12 \mathrm{~m}$ ye düşmüştür. 3 Ekim 2007 tarihine ait 1.09m'lik hatanın 1 Ekim 2007 tarihinde 
göl su seviye yer gözlem ölçümlerinde bulunan $1.02 \mathrm{~m}$ lik seviye düşüklüğünden kaynaklandığı düşünülmektedir. Çalışmada bölgesel ve global EMG2008 jeoid yükseklikleri arasında kullanılan $0.76 \mathrm{~m}$ fark Rao vd. [6] belirtilen aralıktadır. Çalışmadaki bulgu, Jiang vd. [4]'da belirtilen altimetre verilerinden hesaplanacak su seviyelerinin doğruluğunun arttırılması için jeoid düzeltmelerinin gerekliliğini desteklemektedir.

Deniz buzlarının izlenmesi ICESat uydusunun birinci görevi olması [5] ve uydu üzerindeki lazerlerde çıkan arızalardan dolayı görev güncellemeleri nedenlerinden, kutup bölgeleri dışındaki çalışma alanları üzerinde veri elde edilme imkanı büyük ölçüde azalmıştır. Bununla beraber, mevcut ICESat verileri ile değerli bir çok uygulama yapılabileceği bu çalışmada gösterilmiştir. Bu çalışmada önerilen metodoloji, ICESat'ı takip edecek uydu görevlerine kolaylıkla uygulanabileceği gibi, ICESat'1 takip edecek ICESat2'in bilimsel hedef ve misyonu olan "Diğer Yeryüzü gözlemleme sistemlerinin yararını arttırmaya yönelik destekleyici ölçümler [41]” ile de örtüşmektedir.

\section{Teşekkür}

Yazarlar, MOD10A1 ve ICESat GLA14 verilerini sağlayıcısı National Snow and Ice Data Center'a teşekkür ederler. Göl su seviye yer gözlem değerleri DSİ'nden ücreti mukabilinde temin edilmiştir.

\section{Kaynaklar}

[1] The USGS Water Science School, https://water.usgs.gov/edu/gallery/watercyclekids/earth-water-distribution.html, 2020.

[2] Duan Z., Bastiaanssen W. G. M., Estimating water volume variations in lakes and reservoirs from four operational satellite altimetry databases and satellite imagery data. Remote Sensing of Environment 134:403-416.DOI:10.1016/j.rse.2013.03.10, 2013

[3] Zhang, G., Xie H., Duan S., Tian, M., and Yi, D., Water level variation of Lake Qinghai from satellite and in situ measurements under climate change, J of Applied Remote Sensing, 2011

[4] Jiang L., Andersen O. B., Nielsen K., Zhang G., Bauer-Gottwein P., Influence of local geoid variation on water surface elevation estimates derived from multi-mission altimetry for Lake Namco, Remote Sensing of Environment, Volume 221, 2019, Pages 65-79, https://doi.org/10.1016/j.rse.2018.11.004.

[5] ICESat. https://icesat.gsfc.nasa.gov/icesat/index.php (Son ulaşım 16 Eylül 2019)

[6] Rao, B . S., Kumar, G., A. N., Krishna P., V., S., S., N., Srinivasulu, P., Venkataraman V., R., Evaluation of EGM 2008 with EGM96 and its utilization in Topographical Mapping Projects., J. Indian Soc. Remote Sens., 40(2):335-340, doi:10.1007/s12524011-0131-1, 2012

[7] Kılıçoğlu, A., Direnç, A., Simav, M., Lenk, O., Aktug, B., Yildiz, H. Evaluation of The Earth Gravitational Model 2008 in Turkey. 2019, https://www.harita.gov.tr/yuksismod/images/egitim/beb3eda36d64806.pdf 
[8] Yilmaz., N. ve Karaali,. C., Comparison of global and local gravetric models in Turkey. Scientific and Research Essays., 5(14), 1829-1839, 2010

[9] Tekeli, A. E. Augmenting in situ lake level measurements with Earth observation satellites. Teknik Dergi, 29 (6), 0-0. DOI: 10.18400/tekderg.341316, 2018

[10] Ramsar Sites Information Service, Lake Burdur, https://rsis.ramsar.org/ris/658, 2019.

[11] Google Earth Pro V.7.3.2, 2019.

[12] Yiğitbaşıŏlu, H., Uğur, A., Burdur Gölü Havzasında Arazi Kullanım Özelliklerinden Kaynaklanan Çevre Sorunları, Ankara Üniversitesi Çevrebilimleri Dergisi, Cilt 2, Sayı 2, 129-143, 2010.

[13] DMİ 2019 , https://www.mgm.gov.tr/veridegerlendirme/il-ve-ilceleristatistik.aspx?k=A\&m=BURDUR

[14] Kaya, L., G., Yücedağ, C., Duruşkan, Ö., Burdur Gölü Havzasının Çevresel Açıdan İrdelenmesi, Mehmet Akif Ersoy Üniversitesi Fen Bilimleri Enstitüsü Dergisi 6(1): 610 (2015).

[15] Keskin, M., E., Taylan, E., D., Eğirdir ve Burdur Gölleri Su Seviyelerinde Olasi Azalma Eğilimleri, 4. Su Yapıları Sempozyumu, sayfalar: 489-499, 2015.

[16] Ataol, M. Burdur Gölü’nde Seviye Değişimleri, Coğrafi Bilimler Dergisi, 8 (1), 77-92, 2010.

[17] Yiğitbaşoğlu, H., Uğur, A., Burdur Gölü’nün Jeoekolojik Özellikleri ve Sorunları, TURQUA Türkiye Kuvaterner Sempozyumu V, sayfalar: 100-103, 2005.

[18] Yıldırım, Ü., Uysal, M. (2011). Changes in the Coastline of the Burdur Lake Between 1975 and 2010. International Symposium on Environmental Protection and Planning: Geographic Information Systems (GIS) and Remote Sen-sing (RS) Applications (ISEPP) 28-29 June 2011, Izmir-Turkey.

[19] Şener, E., Morova, N., Bulanık Mantık ve Doğrusal Regresyon Analizleri ile Burdur Gölü Su Seviyesi Değişimlerinin Modellenmesi, Süleyman Demirel Üniversitesi, Fen Bilimleri Enstitüsü Dergisi, 15-1( 2011),60-66

[20] Zwally, H. J., Schutz, B., Abdalati, W., Abshire, J., Bentley, C., Brenner, A., et al., ICESat's laser measurements of polar ice, atmosphere, ocean, and land, Journal of Geodynamics, 34(3-4), 405-445, 2002.

[21] Spinhirne, J. D., S. P. Palm, W. D. Hart, D. L. Hlavka, and E. J. Welton, Cloud and aerosol measurements from GLAS: Overview and initial results, Geophys. Res. Lett., 32, L22S03, 2005, doi:10.1029/2005GL023507.

[22] NSIDC, https://nsidc.org/sites/nsidc.org/files/technicalreferences/GLAS_ATBD_Range_and_Range_Distribution_v7_08_2012.pdf, (Son ulaşım 16 Eylül 2019)

[23] Kwok, R., Zwally, H. J., Yi, D., ICESat observations of Arctic sea ice: a first look. Geophysical Research Letters, 31, L16401, 2004 
[24] Srivastava, P., Bhambri, R., Kawishwar, P., Dobhal, D. P., Water level changes of high altitude lakes in Himalaya-Karakoram from ICESat altimetry, J. Earth Syst. Sci.122, 1533-1543, 2013.

[25] Khvorostovsky, K., Rampal, P., On retrieving sea ice freeboard from ICESat laser altimeter, The Cryosphere, 10, 2329-2346, 2016.

[26] Song, C., Huang, B., Ke, L., Heterogeneous change patterns of water level for inland lakes in High Mountain Asia derived from multi-mission satellite altimetry, Hydrological Processes, 29, 2769-2781, 2015, doi:10.1002/hyp.10399

[27] Zhang, G. ,Xie, H., Kang, S. ,Yi, D. and Ackley, S. F., Monitoring lake level changes on the Tibetan Plateau using ICESat altimetry data (2003-2009), Remote Sens. Environ, 115(7), 1733-1742, 2011.

[28] Song C, Huang B, Ke L. 2013. Modeling and analysis of lake water storage changes on the Tibetan Plateau using multi-mission satellite data. Remote Sensing of Environment 135: 25-35. DOI: 10.1016/j. rse.2013.03.013.

[29] MODIS. http://modis.gsfc.nasa.gov/data/dataprod/mod10.php (Son ulaşım 16 Eylül 2019)

[30] Hall, D. K., Riggs, G. A., Salomonson, V. V., Development of methods for mapping global snow cover using moderate resolution imaging spectroradiometer data, Remote Sens Environ, 54:127-14, 1995.

[31] Pu, Z., Xu, L., Salomonson, V. V., MODIS/Terra observed seasonal variations of snow cover over the Tibetan Plateau, Geopyhs Res Lett, 34:L06706., 2007 doi:10,1029/2007GL029262

[32] Gafuorov A., Vorogushyn S., Farinotti D., Duethmann D., Merkushkin A., Merz B., Snow-cover reconstruction methodology for mountainous regions based on historic in situ observations and recent remote sensing data, The Cryosphere, 9, 451-463, 2015.

[33] Xu W., Ma H., Wu D., Yuan W., Assessment of the Daily Cloud-Free MODIS SnowCover Product for Monitoring the Snow-Cover Phenology over the Qinghai-Tibetan Plateau, Remote Sens, 9(6),585, 2017

[34] Tekeli, A. E., Akyürek, Z, Şorman, A. A., Şensoy, A., Şorman, A. U., Using MODIS snow cover maps in modeling snowmelt runoff process in the eastern part of Turkey, Remote Sens Environ, 97, 216-230, 2005.

[35] Tekeli, A. E., Sensoy, A., Sorman, A. A., Akyurek, Z., Sorman, A. U., Accuracy assessment of MODIS daily snow albedo retrievals with in situ measurements in Karasu Basin, Turkiye, Hydrological Processes, 20, 705-721, 2006.

[36] Uysal G., Şorman A. A., Şensoy A., 2016. Streamflow Forecasting Using Different Neural Network Models with Satellite Data for a Snow Dominated Region in Turkey, Procedial Engineering 154, 1185-1192, 12th International Conference on Hydroinformatics, HIC 2016, 21-26 August 2016 
[37] Uysal G., Şensoy A., Şorman A. A., 2016. Improving daily streamflow forecasts in mountainous Upper Euphrates basin by multi-layer percoptron model with satellite snow products . $\quad$ J. http://dx.doi.org/10.1016/j.jhydrol.2016.10.037

[38] Sorman A. A., Uysal G., Sensoy A., Probabilistic Snow Cover and Ensemble Streamflow Estimations in the Upper Euphrates Basin, Journal of Hydrology and Hydromechanics, 67,1,82-92, https://doi.org/10.2478/johh-2018-0025

[39] Hall, D. K., V. V. Salomonson, and G. A. Riggs. 2006. MODIS/Terra Snow Cover Daily L3 Global 500m Grid, Version 5. Boulder, Colorado USA. NASA National Snow and Ice Data Center Distributed Active Archive Center. doi: https://doi.org/10.5067/63NQASRDPDB0.

[40] Koçıbay O. Burdur tarihi, https://www.academia.edu/32247710/Burdur_Gölü (Last accessed 06 Eylul 2019).

[41] ICESat2. http://icesat.gsfc.nasa.gov/icesat2/science_objs.php (Last accessed 20 February 2017). 